\title{
Outro lugar para a mulher em Correio feminino, de Clarice Lispector
}

Another position for women in Correio feminino, by Clarice Lispector

\author{
Yvonélio Nery Ferreira \\ Universidade Federal do Acre - UFAC - Cruzeiro do Sul - Acre - Brasil
}

Marília Simari Crozara

Universidade Federal de Uberlândia - UFU - Uberlândia - Minas Gerais - Brasil

\begin{abstract}
Resumo: Os temas do amor e da sedução foram abordados desde a Antiguidade Clássica por diferentes escolas artísticas e perpetuaram-se ao longo da história como assuntos recorrentes, inclusive na contemporaneidade. Neste estudo, objetivamos realizar apontamentos sobre a elaboração do feminino quanto a tais questões, mediante a obra Correio Feminino (2006), de Clarice Lispector. Esse livro corresponde a uma seleção de crônicas publicadas nos jornais Correio da Manhã, O comício e Diário da Noite. A obra foi organizada em cinco seções, valendo-se das regularidades com que a autora busca, no papel de artífice da palavra, elaborar reflexões junto às mulheres sobre a natureza que as constitui. Pensando nisso, analisamos a seção "Aulas de sedução" e discutimos os apontamentos realizados por Lispector sobre o posicionamento da mulher brasileira, das décadas de 1950 e 1960, quando oferece conselhos sobre beleza, moda, sedução e feminilidade. Para tanto, utilizamos as contribuições teóricas de Heloísa Buarque de Hollanda (1992), Lúcia Osana Zolin (2005) e de outros estudiosos.
\end{abstract}

Palavras-chave: Feminino. Feminismo. Correio feminino. Clarice Lispector.

Abstract: The themes of love and seduction have been approached since Classical Antiquity by different artistic schools and have perpetuated throughout history as recurrent subjects, including in contemporary times. In this study, we intended to make notes on the construction of the feminine, regarding such questions, through the oeuvre Correio Feminino (2006), by Clarice Lispector. This book corresponds to a selection of chronicles published in the newspapers Correio da Manhã, O Comício and Diário da Noite. The book was organized in five sections, making use of the regularities with what the author seeks, in the role of the word's artificer, to elaborate reflections with women about the nature that embody them. With that in mind, we analyzed the section "Aulas de sedução" and discussed the notes made by Lispector about the position of Brazilian women, from the 1950s and 1960s, when she offers advices on beauty, fashion, seduction and femininity. For this purpose, we used the theoretical contributions of Susana Bornéo Funck (1994), Heloísa Buarque de Hollanda (1992), Lúcia Osana Zolin (2005) and other researchers.

Keywords: Feminine. Feminism. Correio Feminino. Clarice Lispector. 


\section{Introdução}

Ao longo da história ocidental, inúmeros discursos de legitimação de diferenças e de supremacia dos homens sobre as mulheres foram elaborados, aprimorados e postos em prática, moldando pensamentos, atitudes e comportamentos que, até hoje, ditam regras que tolhem e afligem grande parte da sociedade. Desde a mitologia grecolatina, passando pelas tradições judaico-cristãs, caminhando pela noção de antropocentrismo, buscouse evidenciar o caráter inferior e submisso das mulheres, correspondendo essas práticas a uma distorção de realidade. Tal ideologia procurou acomodar o sujeito-mulher, bem como a outras minorias como negros, homossexuais, indígenas, apenas para citar algumas, no lugar de subalternidade ao homem ocidental, branco e heterossexual. Diante disso, o crescimento/expansão do feminismo, em linhas gerais, funciona como uma consciência crítica às tensões e contradições que impulsionam esse universo.

Considerando esse descompasso entre 0 lugar sempre ocupado pelo homem frente à mulher, faz-se necessário também sublinhar que esse mesmo processo ocorreu na história da literatura. Segundo Lúcia Osana Zolin:

Historicamente, o cânone literário, tido como um perene e exemplar conjunto de obras-primas representativas de determinada cultura local, sempre foi constituído pelo homem ocidental, branco, de classe média/alta; portanto, regulado por uma ideologia que exclui escritos das mulheres, das etnias nãobrancas, das chamadas minorias sexuais, dos segmentos sociais menos favorecidos etc. Para a mulher inserirse nesse universo, foram precisos uma ruptura e o anúncio de uma alteridade em relação a essa visão de mundo centrada no logocentrismo e no falocentrismo. (ZOLIN, 2005, p. 275).

Tradicionalmente, até meados dos anos de 1970, o lugar da crítica literária era destinado aos homens. No entanto, com o advento dos movimentos feministas, ocorridos no mundo e refletidos no Brasil, foi possível realizar um resgate de inúmeras autoras apagadas e silenciadas pela cultura da misoginia.
Além disso, esse processo viabilizou a "leitura a contrapelo" de autoras como Cecília Meireles, Raquel de Queiroz, Clarice Lispector, entre outras.

Em "Gênero", Maria Consuelo Cunha Campos (1992) afirma que a autoria feminina é elaborada por meio de espaços produtores de sentidos concernentes à marginalização/opressão do feminino. Nesse sentido, pode-se dizer que a escrita da mulher percorreu três estágios para a sua fundamentação: o primeiro é marcado pela atitude da mulher ao imitar a escrita masculina e adotar pseudônimos, vestuários e padrão de conduta do gênero oposto. O segundo estágio corresponde ao momento de luta feminina por direitos, mediante uma escrita de protesto em relação à exclusão e ao rebaixamento sofridos. A partir dos anos de 1960, é possível evidenciar os traços de uma terceira fase na escrita feminina, marcada, então, pela conscientização, pela autoafirmação da escrita-mulher e pela diferenciação de todo o gênero feminino frente ao masculino.

Nesse contexto de fundamentação da escrita feminina, é possível dizer que Clarice Lispector elabora uma "escrita de protesto" a favor do feminino, que implica em uma conscientização existencial, por meio da identificação do leitor com as narradoras de suas crônicas, inicialmente publicadas nas páginas do jornal Comício, em 1952. Assim, tentar ler a cultura ocidental a partir de olhares ficcionais poderia garantir 0 entendimento histórico da enunciação da mulher. Mas, para se chegar a esse momento, é necessário fazermos aqui um breve percurso histórico quanto à politização e conscientização do espaço social feminino com base na evolução do movimento feminista brasileiro, para que, assim, possamos entender um pouco melhor o lugar da mulher na sociedade contemporânea.

\section{Sobre feminismo e feminino}

Em princípio, o termo "feminismo", no Brasil, sempre carregou em seu seio a marca do preconceito e, mesmo tendo conquistado vitórias, não conseguiu se impor como motivo de orgulho para a maioria das mulheres. O antifeminismo, por vezes, era (e ainda é) tão forte que atribuía às feministas o caráter contrário 
ao que se pressupunha ser o feminino. Por receio de estigmatizações, várias escritoras e outras mulheres brasileiras rejeitaram ser chamadas de feministas. Essa visão estereotipada é, no entanto, decorrente do desconhecimento dos ideais desse movimento, ainda pouco compreendido.

A história do feminismo no Brasil pode ser abordada a partir de quatro momentos em que 0 movimento atingiu seu ápice: os anos de 1830, 1870, 1920 e 1970. Há, no entanto, entre essas datas, um entremeio temporal de mais ou menos cinquenta anos no qual essas ideias ficaram em estado de letargia.

$\mathrm{O}$ primeiro momento carrega em seu bojo a luta das mulheres pelo direito básico de ler e de escrever (até então exclusivo ao sexo masculino), cuja conquista fora registrada na legislação de 1827, que autorizava a abertura de escolas públicas femininas. Antes disso, poucos eram os lugares disponíveis para que as mulheres fossem instruídas. Segundo Constância Lima Duarte,

[...] foram aquelas primeiras (e poucas) mulheres que tiveram uma educação diferenciada, que tomaram para si a tarefa de estender as benesses do conhecimento às demais companheiras, e abriram escolas, publicaram livros, enfrentaram a opinião corrente que dizia que mulher não necessitava saber ler nem escrever. (DUARTE, 2003, p. 153).

Eis o segundo estágio do movimento feminista brasileiro em meados de 1870. Na busca pela educação escolar, surgem, no Rio de Janeiro e em outros locais do país, jornais e revistas de caráter notoriamente feminista, que não publicavam apenas artigos referentes à vida doméstica da mulher ou romances de folhetins e poemas, mas levantavam bandeiras clamando pelo acesso ao Ensino Superior e à implantação do trabalho remunerado para as mulheres. Dentre outras temáticas abordadas por esses jornais, destacam-se assuntos como a dependência econômica feminina ser determinada pela subjugação ao homem, o progresso do país depender também das mulheres, a denúncia da opressão, os protestos contra a insensibilidade masculina, a luta pelo direito ao Ensino Superior, ao divórcio, ao trabalho remunerado e ao voto.
Já na década de 1920, as mulheres continuam buscando sua liberdade, lutando, por exemplo, pelo direito ao voto - que será conseguido somente em 1932, com Getúlio Vargas -, pelo acesso ao Ensino Superior e pela ampliação do mercado de trabalho, abrindo assim espaço para o terceiro momento dos movimentos feministas, ocorrido neste país. Vários anseios feministas foram ridicularizados e sufocados por movimentos masculinos e políticos contrários, como no caso da campanha pelo direito ao voto, que se prolongou até 1928. Para a maioria dos homens, a mulher deveria manter o papel de "dona de casa", pois qualquer outro lhe seria incompatível.

A revolução sexual, da década de 1970, funcionará como um divisor de águas para o quarto momento das lutas feministas. Vários costumes mudaram radicalmente e reivindicações antes consideradas "absurdas" se tornaram práticas normais no seio social. Diante disso, inúmeros encontros foram organizados para discussões acerca do papel da mulher em diferentes setores sociais. Nesse contexto de lutas, o Dia Internacional da Mulher, 8 de março, foi, assim, instituído por iniciativa da ONU no ano de 1977. Vale lembrar que a data já era utilizada desde o início do século XX para celebrar a luta dos direitos das mulheres e vários eventos influenciaram a criação da data, entretanto, dois deles foram determinantes na oficialização do dia 8 de março. O primeiro corresponde ao incêndio na fábrica de roupas Triangle Shirtwaist, em Nova York, em 1911, quando a tragédia levou às capas de jornais as terríveis condições de trabalho a que as mulheres eram submetidas. $O$ segundo evento corresponde à marcha das mulheres russas por pão e paz em 1917, iniciando uma revolução de efeitos globais que reverberam até hoje no mundo.

As conquistas das mulheres no Brasil foram gradativas, embora tardias, e, no final dos anos de 1970 e durante a década de 1980, os estudos sobre a mulher e sua legitimação acadêmica foram consolidados, por meio de simpósios, seminários e encontros, cuja finalidade era a troca de experiências entre os pesquisadores da área que reverberavam as vozes femininas. No entanto, a partir da década de 
1990, observa-se uma acomodação gradativa da militância e o enfraquecimento de uma história que começava a ser escrita. Em princípios dos anos 2000, os debates em torno da mulher se intensificam novamente com discussões em torno de políticas públicas concernentes à descriminalização do aborto, bem como com os protestos relativos às leis sobre 0 estupro ${ }^{1}$. Desta forma, concordamos com Constância Lima Duarte, quando afirma que:

Com certeza vivemos outros e novos tempos, e o movimento feminista parece atravessar um necessário e importante período de amadurecimento e reflexão. O que não se sabe é como retornará na próxima onda. Aliás, nem mesmo é possível saber se haverá outra onda, que formato e dimensões poderia ter. (DUARTE, 2003, p. 168).

Esse breve percurso histórico de politização e conscientização do espaço social feminino aponta para o lugar que a mulher passou a ocupar na sociedade em virtude do movimento feminista. Foi graças a ele que a mulher se inseriu nos mais variados espaços, impondo a sua voz e marcando presença em setores como a crítica literária, até então destinada, quase em sua totalidade, ao domínio masculino. As mulheres passaram a escrever tanto literatura quanto crítica sem temer a rejeição masculina típica de outros tempos. Tornou-se, portanto, imprescindível o resgate da produção literária feminina esquecida até então, o que resultou, no Brasil, na descoberta de obras de inúmeras escritoras do século XIX nunca antes mencionadas pela crítica.

Nas primeiras décadas do século XX, a lista de escritores reconhecidos traz pouquíssimos nomes de mulheres. Já a partir dos anos de 1970 há uma modificação nesse quadro, pois escritoras como Cecília Meireles e Raquel de Queiroz, reconhecidas nacionalmente, fazem com que diversas outras mulheres sejam inseridas no mercado editorial. Mas

1 Em linhas gerais, esses dois temas são questões debatidas e reivindicações dos movimentos feministas atuantes no Brasil. À guisa de exemplificação, até 1994, o Código Penal Brasileiro considerava o aborto um crime passível de prisão para as mulheres que se submetessem ao ato. $O$ crime é desconsiderado em três situações: em caso foi, como destaca Lúcia Helena Viana, sobretudo Clarice Lispector quem inaugurou "uma tradição para a literatura da mulher no Brasil, gerando um sistema de influências que se fará reconhecido na geração seguinte" (1995, p. 172).

Embora não pretendamos classificar a obra de Clarice Lispector como feminista, é inegável que há, em sua produção literária, um questionamento de diversos valores patriarcais, apontando outro caminho ficcional baseado na conscientização do ser humano, ao denunciar uma sociedade guiada por preceitos dos homens, e na valorização do universo feminino. A obra de Lispector é, assim, segundo Zolin, constituída por "narrativas que questionam, por meio de discurso irônico, o modelo patriarcal em que a mulher fica reduzida ao que 0 espaço privado pode the proporcionar" (2005, p. 280).

Tais questões podem ser observadas na coletânea de contos Laços de família (1998), em que algumas narrativas são representativas da tensão existente na relação entre mulher e sociedade. Os contos "Amor" e "A imitação da rosa" são bons exemplos do enquadramento da mulher na vida familiar, que massacra anseios e desejos femininos, aprisionando a consciência crítica e legando à mulher o espaço da obediência a regras basilares da família patriarcal brasileira.

$\mathrm{Na}$ esteira desse pensamento, visualizamos, também, a obra de Lispector destinada à imprensa feminina. Praticavam-se, no início do século $X X$, dois estilos de jornalismo no Brasil: o "tradicional", que propagava a ideia de que a mulher ainda deveria se dedicar às atividades vinculadas ao lar e à família; e o "progressista", defensor dos direitos das mulheres. Essa imprensa feminina de cunho progressista foi, tardia e primeiramente, realizada por homens, como no caso do Jornal de Senhoras, editado, em 1852, na busca de fazer com que o sexo masculino passasse a

de estupro, para a manutenção da vida e na gestação de anencéfalo. A questão voltou a ser debatida nos últimos anos no Brasil, no entanto, o conservadorismo judaico-cristão e a misoginia inviabilizam a implementação de políticas públicas que beneficiem o corpo feminino. 
visualizar e respeitar o novo lugar do feminino que se organizava na sociedade brasileira. Paulatinamente, essa imprensa fomentadora de um olhar libertário para o universo feminino passou a ser elaborada por mulheres.

Entretanto, moda e dicas de como se vestir bem sempre foram temas predominantes da imprensa destinada às mulheres, conteúdo que foi drasticamente alterado pelos escritos jornalísticos de Lispector, que deslocava lugares comuns mediante a crítica aos costumes sociais, visando à equidade entre homens e mulheres. Com efeito, a década de 50 do século $X X$ corresponde a um momento de intensa produção da imprensa feminina no Brasil, haja vista ser desejo da mulher brasileira, que já conseguira o direito ao ensino, discutir as questões relacionadas ao ambiente doméstico e, sobretudo, problematizar os dilemas sentimentais (des)construídos frente a essa (re)formulação social.

Usando uma linguagem simples e acessível a todos os tipos de leitoras, Clarice se valerá dos pseudônimos Tereza Quadros, Helen Palmer e Ilka Soares para ultrapassar o trivial e o corriqueiro, presentes no cotidiano das mulheres brasileiras, conduzindo-as ao lugar da emancipação feminina. É tendo em vista essa perspectiva da desconstrução do senso comum que passaremos à leitura da seção "Aulas de sedução", da obra O Correio Feminino (2006), de Clarice Lispector. Faz-se mister sublinhar que a obra em questão corresponde à reunião (organizada por Aparecida Maria Nunes) das crônicas clariceanas publicadas nos jornais Correio da Manhã, O comício e Diário da Noite.

Ao atentar para a escritura de Clarice Lispector, é notório que sua literatura pode ser observada como retrato do cotidiano feminino em diversas implicações rotineiras, suscitando, por meio de suas personagens, a conscientização, mesmo que momentânea, quanto ao papel de mulher atuante na vida doméstica e na pública.

Além da ficção, Clarice Lispector, como já mencionado, dedicou-se à escrita de crônicas para o público feminino em páginas de alguns jornais brasileiros. A decisão de assinar com pseudônimos revela inicialmente o temor de que tais textos não fossem entendidos e aceitos pelo público de seus livros, uma vez que o teor era bem diferente daquele encontrado em seus escritos já conhecidos e reconhecidos.

Segundo Aparecida Maria Nunes:

Clarice tinha consciência de que não podia esquecer o perfil do público para quem dava conselhos utilitários e ensinava a refletir sobre cenas domésticas e do universo da mulher. A ficcionista sabia também que tinha de manejar uma linguagem mais despojada e adotar um discurso calcado na estética da imprensa feminina, construída no tom de conversa íntima, afetiva e persuasiva. [...] Assim, seguindo disfarçadamente a natureza dos textos da imprensa feminina, Clarice publicará algumas narrativas, sob a forma de conselhos, receitas e segredos. Textos esses que seguem o paradigma da imprensa feminina, bem ao gosto do status quo. Porém, a página de jornal, ao se tornar espaço de diálogo, aproximando a colunista de sua interlocutora, através do fio condutor "a mulher e o espaço em que vive", em alguns momentos, poderá se transformar em pretexto para a escritora iniciar a leitora. Ao conquistar seu público pelo tom de confidente e conselheira, Clarice Lispector, valendose dos "pequenos textos inofensivos" sobre o comer, o vestir, o enfeitar-se, instiga sua leitora a refletir sobre as duas realidades em que se estrutura a realidade: o mundo das simulações e o da verdadeira natureza das coisas. (NUNES, 2006, p. 7-8).

$\mathrm{Na}$ seção "Aulas de sedução", Clarice Lispector apresenta métodos da sedução a suas leitoras. O estilo elaborado é claro e didático, e, quase sempre, as informações são tratadas como verdades inquestionáveis. As possibilidades descritas para que a mulher não apenas se sinta, mas se apresente sedutora são diversas: trato na aparência física, personalidade cativante, alegre e delicada, feminilidade, postura corporal, tons e cores de roupas mais adequados, como se perfumar, entre outras dicas, que buscavam ensinar e despertar em suas leitoras a arte da sedução.

Em crônicas como "Sedução e feminilidade", "Qualidades para tornar a mulher mais sedutora", "Descobrindo o próprio 'sex-appeal'", podemos 
observar as sutilezas de discursos que perpassam a atitude feminina aliada à valorização da mulher, indicando uma possível postura feminista. Em momentos como o apontado na crônica "Qualidades para tornar a mulher mais sedutora", Clarice Lispector afirma que

Os tempos modernos trouxeram a emancipação da mulher em quase todos os campos. Eis um grande bem. No entanto, muita confusão se faz em torno disto e o que se vê é que muitas representantes do sexo feminino entendem que ser emancipada e ter personalidade marcante é imitar os homens em todas as suas qualidades $\mathrm{e}$ defeitos. (LISPECTOR, 2006, p. 100).

Nesse sentido, é perceptível o destaque dado ao papel que a mulher estava assumindo na sociedade naquele momento. As nomeadas "aulinhas" de Lispector tinham o papel didático de direcionar o comportamento da "mulher esclarecida", que vivenciava o nascer de uma emancipação. A escritora não apresenta para a leitora dessas crônicas a importância da différance ${ }^{2}$ e acaba por comparar a mulher moderna àquela que busca se igualar ao homem em tudo. Com efeito, quando a autora trata de "quase" todas as emancipações femininas, ela acena, mesmo que timidamente, em favor das causas feministas que se tornariam representativas nos anos subsequentes. Trata-se de uma escrita repleta de eufemismos e ironias sutis.

No entanto, ao mesmo tempo em que Clarice Lispector apresentava à suas leitoras uma visão de autonomia e emancipação feminina, ela também afirmava, de forma coerente ao discurso ainda bastante machista da época, que a feminilidade era algo fundamental para a arte da sedução e dependia da alegria, da delicadeza dos gestos, das atitudes e das palavras dóceis das mulheres. Não podemos nos esquecer que, mesmo que a sociedade brasileira

2 Considerando as ponderações de Stuart Hall (2003), a différance é uma noção de Jacques Derrida, que "[...] não funciona através de binarismos, fronteiras veladas que não separam finalmente, mas que são também places de passage, e significados que são posicionais e relacionais, sempre em deslize ao longo de um espectro sem começo nem fim. A diferença, caminhasse para a valorização feminina, essa realidade, como acontece até hoje, era distante, e que Clarice escrevia para leitoras pertencentes a famílias patriarcais e conservadoras. Foi, pois, respondendo a esse contexto que a autora afirma que, para ser sedutora, a mulher não deveria se impor com gritos e com exigências, mas colocando-se ao lado de seu companheiro, para ajudá-lo, incentivá-lo e compreendê-lo.

Aliar um discurso feminino a uma postura aparentemente feminista parece contraditório, mas é importante ressaltar que Clarice Lispector não se preocupa em levantar bandeiras defendidas pelas feministas na escritura de suas crônicas, apenas evidencia a autonomia feminina frente a uma nova estrutura social advinda da evolução e das conquistas adquiridas ao longo de séculos, conquistas que permitiram à mulher um lugar na família e na sociedade, independentemente do homem.

Assim, é possível entrever que, a todo momento, a autora procura despertar em suas leitoras as duas posturas, a de mulher atraente e sedutora e a de mulher autônoma e consciente de seu papel, considerando o contexto socio-histórico de suas leitoras. Mas o axioma predominante nessas crônicas é o de que "A mulher deve ser primeiro que tudo feminina" (LISPECTOR, 2006, p. 100). De forma coerente a esse discurso, há momentos que Lispector critica as mulheres que veem nessa autonomia feminina um motivo para perder a feminilidade, se igualando ao homem fisicamente e em gestos, como observado neste trecho da crônica "Sedução e feminilidade": "Muitas mulheres modernas adotam atitudes masculinizadas, palavreado grosseiro, liberdade exagerada de linguagem ou de maneiras, e julgam que isso é bonito, que vão encantar os homens." (LISPECTOR, 2006, p. 95). Ao apontar essa conduta, a autora sinaliza que a sociedade e as

sabemos, é essencial ao significado, e o significado é crucial à cultura. [...] Sempre há o "deslize" inevitável do significado na semiose aberta de uma cultura, enquanto aquilo parece fixo continua a ser dialogicamente reapropriado. A fantasia de um significado final continua assombrada pela 'falta' ou 'excesso', mas nunca é apreensível na plenitude de sua presença a si mesma.” (HALL, 2003, p.33). 
mulheres de seu tempo têm alterado sua conduta e maneira de perceber o mundo circundante.

\section{Considerações finais}

Como podemos notar, em suas crônicas destinadas às "Aulas de sedução", Clarice Lispector perpassa as diversas facetas da mulher na sociedade brasileira de seu tempo, destacando-a como um ser que busca a emancipação nas décadas de 50 e 60 do século XX. Apesar dessa nova postura, a autora afirma a necessidade dessa mulher não perder sua feminilidade, atitude ainda vinculada com o discurso de seu tempo. Entretanto, as dicas dadas na seção da obra de Lispector reforçam aquilo que está aparente e subentendido na mulher, em seus gestos, atitudes e posturas, visando a um único aprendizado: a arte da sedução, mas valendo-se desse assunto para criar um imaginário feminino autônomo, independente e em defesa do espaço da mulher no bojo da sociedade patriarcal brasileira.

\section{Referências}

CAMPOS, M. C. C. Gênero. In. JOBIM, J. L. (Org.). Palavras da crítica. Rio de Janeiro: Imago, 1992.

DELEUZE, G; GUATARI, F. Mil mesetas - capitalismo y esquisofrenia. Valencia: Pre-textos, 2004.

HALL, S. Da diáspora: identidades e mediações culturais. Belo Horizonte: UFMG, 2003.

HOLLANDA, H. B. Os estudos sobre a mulher e a literatura no Brasil: uma primeira avaliação. In: COSTA, A. O; BRUSCHINI, C. (Orgs.). Uma questão de gênero. Rio de Janeiro: Rosa dos tempos; São Paulo: Fundação Carlos Chagas, 1992.

LISPECTOR, C. Correio feminino. In: NUNES, A. M. (Org.). Correio feminino. Rio de Janeiro: Rocco, 2006.

LISPECTOR, C. Laços de família. Rio de Janeiro: Rocco, 1998.

VIANA, L. H. Por uma tradição do feminismo na literatura brasileira. In: Seminário Nacional Mulher e Literatura, 1993, Natal, Anais... Natal: UFRN, Universitária, 1995.

ZOLIN, L. O. Crítica feminista. In: ZOLIN, L. O; BONNICI, T. (Orgs.). Teoria literária: abordagens históricas e tendências contemporâneas. 2 ed. rev. e ampl. Maringá: Eduem, 2005.

ZOLIN, L. O. Literatura de autoria feminina. In: ZOLIN, L. O; BONNICI, T. (Orgs.). Teoria literária: abordagens históricas e tendências contemporâneas. 2 ed. rev. e ampl. Maringá: Eduem, 2005.

NERY FERREIRA, Yvonélio; SIMARI CROZARA, Marília. Outro lugar para a mulher em Correio feminino, de Clarice Lispector. Signo, Santa Cruz do Sul, v. 45, n. 84, p. 3743, nov. 2020. ISSN 1982-2014. Disponível em:

<https://online.unisc.br/seer/index.php/signo/ article/view/15384>

doi:https://doi.org/10.17058/signo.v45i84.153 84. 